\title{
ASPECT BASED SENTIMENT ANALYSIS DATA KUESIONER DI RUMAH SAKIT MUHAMMADIYAH LAMONGAN MENGGUNAKAN ALGORITMA K-NN.
}

\author{
Mustain $^{1}$, Hartarto Junaedi ${ }^{2}$, Endang Setiati ${ }^{2}$ \\ ${ }^{1}$ Teknik iformatikan, fakultasi teknik universitas islam lamongan, ${ }^{2}$ Teknologi Informasi Institut Sains dan \\ Teknologi Terpadu Surabaya, ${ }^{3}$ Teknologi Informasi Institut Sains dan Teknologi Terpadu Surabaya, \\ Jln Veteran 53 A Lamongan08113595996 \\ E-mail:mustain@unisla.ac.id
}

\begin{abstract}
ABSTRAKS
Kesulitan untuk mengorganisir data kuesioner yang bersifat konvensional melatarbelakangi penelitian ini. Oleh karena itu dibuat sistem yang memudahkan pengelompokan data kuesioner secara otomatis yang lengkap dengan sentimen yang terkandung didalamnya.Dataset yang digunakan dalam penelitian ini adalah data kuesioner rumah sakit Muhammadiyah lamongan. Penelitian ini hanya menangani kuesioner yang berbentuk teks. Data dengan fisik kertas direkap kemudian diinput ke database lengkap dengan kategori unit kerja dan sentiment. Selanjutnya dataset tersebut di dilakukan pre-prosesing yang meliputi penanganan negasi case folding, tokenizing, filtering dan stemming. Sebagai data uji komentar dari kuesioner akan dilakukan preprosesing selanjutnya dihitung tingkat kemiripan document dengan menggunakan metode K- Nearest Neighbor dan Vector Space Model.Jumlah data yang ditangani mempengaruhi performa system terutama dari akurasi dan kecepatan pada saat proses klasifikasi. Hasil dari sistem yang dibuat berupa ranking dokumen yang paling mirip dengan dataset berdasarkan urutan nilai cosine similarity. Ujicoba klasifikasi berdasarkan kelas kategori menghasilkan nilai akurasi 91 \%. Ujicoba berdasarkan Kelas Sentimen sebesar 94 \%.dari kombinasi keduanya system berhasil mendapat akurasi sebesar $86 \%$.
\end{abstract}

Kata Kunci: K-nn, Klasifikasi, VSM, Cosine Similarity.

\begin{abstract}
Difficulties to organize conventional questionnaire data are the background of this study. Therefore, a system was created to facilitate the grouping of questionnaire data automatically and completely with the sentiments contained.The dataset used in this study was questionnaire data from the Lamongan Muhammadiyah Hospital. This study only handles questionnaires in the form of text. Data with physical paper is recapped then inputted into a complete database with work unit and sentiment categories. Furthermore, the dataset is pre-processed which includes handling case negation, tokenizing, filtering and stemming. As a comment test data from the questionnaire will be pre-processed then the document similarity level is calculated using the TF IDF, K-Nearest Neighbor method and Vector Space Model.The amount of data handled affects the system performance especially from the accuracy and speed during the classification process. The results of the system are in the form of ranking documents that are most similar to the dataset based on the order of cosine similarity values. Classification tests based on class categories produce an accuracy value of $91 \%$. Trials based on Sentiment Class were $94 \%$. From the combination of the two systems, they managed to get an accuracy of $86 \%$.
\end{abstract}

Keyword : K-nn, Klasifikasi, VSM, Cosine Similarity.

\section{PENDAHULUAN}

\subsection{Latar Belakang}

Perkembangan ilmu pengetahuan dan teknologi kian pesat. Hal tersebut dapat dilihat secara langsung maupun tidak langsung. Perkembangan tersebut telah berdampak pada segala aspek kehidupan manusia. Salah satu diantaranya adalah kemajuan Sistem Informasi didunia yang berkembang sangat pesat termasuk di Indonesia hampir semua perusahaan, pendidikan, instansi pemerintah, termasuk juga rumah sakit sudah memanfaatkan sistem informasi sebagai pengerak manajemennya.

Rumah sakit Muhammadiyah Lamongan yang menjadi rumah sakit terbesar dengan luas lahan $39.428 \mathrm{M}^{2}$, dan luas lantai $\pm 16.959 \mathrm{M}^{2}$, serta dilengkapi dengan 232 tempat tidur, Rumah Sakit Muhammadiyah juga sudah memanfaatkan komputerisasi di semua lini pengelolaanya. Rumah sakit muhammadiyah juga sudah mengunakan jejaring sosial, website, sms gateway, memberikan informasi kepada masyarakat. Untuk menjadi rumah sakit dengan standart di atas rata rata maka tidak mungkin dapat meninggalkan sistem informasi sebagai penyambung hubungan dengan masyarakat.

Informasi yang di terima masyarakat dengan baik berimbas pada banyaknya pasien yang berobat di rumah sakit muhammadiyah Lamongan \pm 10.000 orang per tahun. Untuk menjaga agar kepercayaan masyarakat kepada rumah sakit maka rumah sakit membuka layanan kritik dan saran melalui quisoner dan kotak angket yang di sebar di beberapa titik di rumah sakit. Kritik dan saran yang masuk akan di rekap kemudian di jadikan bahan evaluasi pihak manajemen rumah sakit untuk dapat meningkatkan 
kualitas dari pelayanan yang di berikan rumah sakit kepada masyarakat.

Dari banyaknya data yang masuk kerumah sakit, yang di kelola secara manual yang tentu sangat merepotkan. Dari paparan di atas maka dibuatlah sistem Aspect Based Sentiment Analysis data Kuesioner menggunakan algoritma K-NN untuk memudahkan pengelolahan data dengan jumlah besar, dimana data itu dapat di manfaatkan sebagai referensi pihak manajemen untuk mengambil kebijakan dan menentukan strategi pengembangan jangka panjang.

Adapun dari latar belakang permasalahan yang di hadapi rumah sakit, maka penelitian ini memiliki tujuan dan manfaat sebagai berikut :

1. Menggali informasi yang terkandung didalam laporan masyarakat secara otomatis.

2. Menganalisa sentiment masyarakat kepada rumah sakit muhammadiyah Lamongan.

3. Mengkonversi data yang sifatnya manual kedalam database.

Sedangkan manfaat dari penelitian

1. Bahan evaluasi mutu kepuasan pasien

2. Sebagai bahan referensi untuk menentukan arah kebijakan.

3. Memberikan informasi yang akurat berdasarkan laporan masyarakat.

Bahan laporan tahunan ke direksi rumah sakit muhammadiyah agar dapat di gunakan untuk menentukan kebijakan di tahun mendatang sebagai langkah perbaikan pelayanan rumah sakit.

\section{METODE PENELITIAN}

Adapun metode penelitian yang akan dilakukan adalah supaya memberikan gambaran yang jelas untuk melakukan penelitian ini. Adapun beberapa metode yang dilakukan adalah sebagai berikut :

a. Studi Literatur

Dengan mempelajari buku-buku referensi dan jurnal yang berkaitan dengan permasalahan penelitian yang diangkat serta mencari solusi yang terbaik.Topik bahasan utama yang dibutuhkan diantaranya klasifikasi dengan metode KNN (K-Neares neighbor) dan VSM (Vector Space Model).diantara yang menjadi rujukan.

Tabel 1. Daftar judul referensi yang digunakan

\begin{tabular}{|l|l|l|}
\hline No & Judul & Penulis \\
\hline 1 & sentiment analysis on & Mohammad \\
& twitter data using & Rezwanul \\
& KNN and SVM & Huq, Ahmad \\
& & Ali, Anika \\
& & Rahman \\
\hline
\end{tabular}

Dalam penelitian yang di lakukan oleh Mohammad Rezwanul Huq, Ahmad Ali, dan Anika Rahman yang berjudul sentiment analysis on twitter data using KNN and SVM peneliti mencoba membandingkan metode yang paling memiliki tingkat keakuratan dalam perhitungan. Sebagai bahan penelitian Muhammad rezwanul huq serta timnya menjadikan data di twitter dengan panjang maksimal 140 karakter pembatasan ini di lakukan karena untuk mendapatkan twittan yang ringkas dan ekpresif, yang hebat dari penelitian ini peneliti tidak memanfaatkan emoticon sebagai penanda akan tetapi mengangap emoticon adalah kata yang tidak penting.

b. Analisa

Melakukan uji coba secara teoritis terhadap masalah yang diangkat guna menganalisa apakah rancangan algoritma yang digunakan dapat menghasilkan solusi yang sesuai dengan tujuan penelitian.

c. Implementasi

Membuat program dari hasil rancangan algoritma yang telah dibuat untuk mengimplementasikan serta membuktikan bahwa hasil analisa secara teoritis yang telah dilakukan benar-benar sesuai yang diharapkan.

d. Pengujian

Pengujian dilakukan untuk melihat apakah data yang telah menjadi input akan diproses sesuai dengan output yang diharapkan. Hal ini juga dilakukan untuk mengevaluasi apakah metode yang diusulkan mampu menjawab tujuan yang telah usulkan.

e. Dokumentasi

Merupakan langkah akhir, penyusunan laporan mulai dari latar belakang permasalahan sampai dengan pengambilan kesimpulan akan dijelaskan dalam tahap dokumentasi ini.

\section{ARSITEKTUR SISTEM}

Arsitektur sistem yang digunakan untuk mengambarkan sistem kerja yang digunakan dalam proses analisa dan implementasi. Dimulai dari pengumpulan data konvensional dari pasien kemudian dijadikan data file excel yang dapat di masukan kedalam database selanjutnya sebelum dilakukan preprocessing dimana dalam arsitektur disebut juga dengan istilah ekstrasi data maka terlebih dahulu dilakukan pelabelan secara manual terhadap data mentah sesuai dengan kelas yang sesuai dengan pesan yang ditulis, sekaligus pelabelan kelas sentimennya. Selanjutnya data disimpan menjadi data berlabel. Ekstraksi data dan diteruskan pada proses pengolahan data latih atau training ini nanti yang akan dijadikan penentu kelas klasifikasi terhadap data baru. Semua proses yang di jelaskan di atas itu termasuk proses preprocessing.

Setelah mendapatkan sebuah data training maka tahap selanjutnya adalah proses klasifikasi dimana untuk proses ini dilakukan dengan mengunakan data kuesioner dari pasien. Proses klasifikasi akan dilakukan dengan cara merubah pesan menjadi matrik dokumen agar dapat dihitung dengan mengunakan algoritma K-NN untuk mencari kelas 
apa yang cocok. Ada beberapa kelas diantaranya apotik, kebersihan, jadwalpraktek, fasilitas, pelayanan dan lain-lain. Proses selanjutnya dilakukan proses pengujian klasifikasi analisis sentimentnya berdasarkan kelas prositif, negative dan netral. Untuk mempermudah dalam memahami berikut peneliti sajikan desain sistem pada gambar 1 .

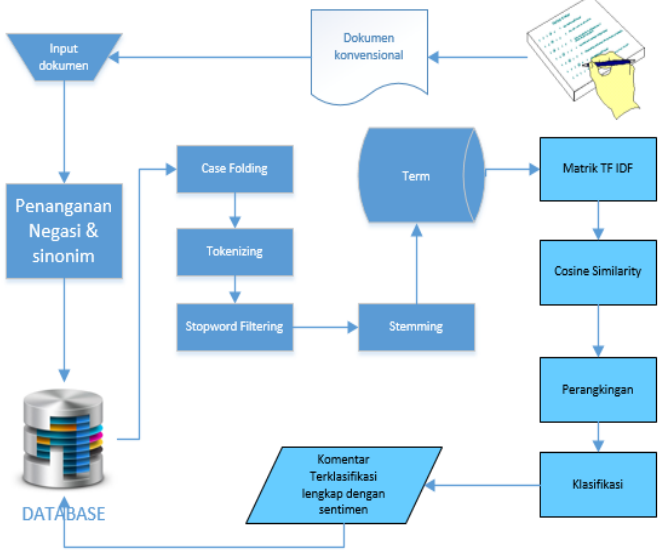

Gambar 1. Desain Arsitektur Sistem

\subsection{Analisa Kebutuhan Data}

Data yang dipakai dalam penelitian ini adalah bersumber dari kuesioner yang di berikan oleh pihak rumah sakit untuk setiap pasien yang di rawat dan bersumber dari kotak angket yang disediakan disetiap lorong rumah sakit. data yang berasal dari kuesioner hanya akan di ambil pesan yang tertulis di kolom komentar.

Data yang akan dipakai sebagai data penelitian ini sebanyak 1700 record terdiri data latih atau data training yang berjumlah 1400 record yang terbagi menjadi enam kelas sedangkan untuk dari uji sebanyak 300 record. Hal ini dilakukan agar pengujian akan lebih mendapatkan hasil yang maksimal. Selain itu kebutuhan data yang dipakai pada penelitian ini disesuaikan dengan data yang dibutukan saat perencanaan awal dan mempercepat proses pelabelan secara manual, karena pada penelitian ini adalah model supervised learning. Artinya butuh data latih untuk menentukan klasifikasi yang baik dan akurat. Semakin banyak data latih semakin baik pulan hasil dari klasifikasi yang diperoleh, namun butuh waktu yang lama dalam proses pelabelannya. Berikut rincian dari data yang digunakan.

Tabel 3. Rincian Data Latih

\begin{tabular}{|c|c|c|c|c|c|}
\hline No & Kategori & Jumlah & Positif & Negatif & Netral \\
\hline 1 & Apotik & 44 & 2 & 38 & 3 \\
\hline 2 & Kebersihan & 56 & 10 & 43 & 3 \\
\hline 3 & $\begin{array}{c}\text { Jadwal } \\
\text { praktek }\end{array}$ & 83 & 3 & 74 & 6 \\
\hline 4 & Fasilitas & 225 & 40 & 169 & 14 \\
\hline 5 & Pelayanan & 770 & 513 & 237 & 64 \\
\hline 6 & Lain-Lain & 222 & 104 & 84 & 34 \\
\hline \multicolumn{7}{|c|}{ Total } & 1400 & 672 & 645 & 124 \\
\hline
\end{tabular}

\section{KLASIFIKASI DOKUMEN}

Preprosesing data dilakukan setelah pasien atau pengunjung rumah sakit mengisi form yang telah disediakan oleh pihak rumah sakit. tahapan-tahapan dalam preprosesing meliputi case folding, tokenizing, filtering dan steamming. Contoh dokumen yang terkategori lengkap dengan sentiment dan query yang ditunjukan pada tabel di bawah ini.

Tabel 4. Rincian Data Latih

\begin{tabular}{|c|c|c|c|}
\hline$D$ & Komentar & Sentimen & Kategori \\
\hline D1 & $\begin{array}{l}\text { Semua bagus, } \\
\text { hanya obat lama } \\
\text { antrianya } 9\end{array}$ & Netral & Apotik \\
\hline D2 & $\begin{array}{l}\text { Pendaftaran dan } \\
\text { DEPO farmasi } \\
\text { lama. }\end{array}$ & Negatif & Apotik \\
\hline D3 & $\begin{array}{l}\text { Ruang perawatan } \\
\text { dan kamar mandi } \\
\text { kurang bersih. }\end{array}$ & Negatif & Kebersihan \\
\hline D4 & $\begin{array}{l}\text { Pelayanan baik } \\
\text { dan } \\
\text { menyenangkan } \\
\text { susternya ramah. : }\end{array}$ & Positif & Pelayanan \\
\hline D5 & $\begin{array}{l}\text { Layananpetugas } \\
\text { pendaftaran lama, } \\
\text { kurang cekatan. }\end{array}$ & Negatif & Pelayanan \\
\hline $\begin{array}{l}\text { quer } \\
\mathrm{y}\end{array}$ & $\begin{array}{ll}\text { Layanan } & \text { obat } \\
\text { sangat lama. } & \\
\end{array}$ & $?$ & $?$ \\
\hline
\end{tabular}

\subsection{Case Folding}

Tidak semua dokumen teks konsisten dalam menggunakan huruf kapitan. Oleh karena itu, peran case folding dibutuhkan dalam mengkonversi keseluruhan teks dalam dokumen menjadi bentuk standar "Lowercase" sebagai contoh user yang ingin mendapatkan informasi "pelayanan" dan mengetikan "PELAYANAN" tetap di berikan kata pelayanan. Case folding adalah mengubah semua huruf dalam dokumen menjadi huruf kecil. Hanya huruf "a" sampai dengan huruf " $z$ " yang diterima. Karakter selain huruf dihilangkan dan dianggap delimiter.

\subsection{Tokenizing}

Tahap Tokenizing adalah tahap pemotongan string input berdasarkan tiap kata yang menyusunnya.Tokenisasi secara garis besar memecah sekumpulan karakter dalam suatu teks ke dalam satuan kata, bagaimana membedakan karakter-karakter tertentu yang dapat diperlakukan sebagai pemisah kata atau bukan.Sebagai contoh karakter whitespace, seperti enter, tabulasi, spasi dianggap sebagai pemisah kata. Namun untuk karakter petik tunggal ('), titik (.), semikolon (;), titk dua (:) atau lainnya, dapat memiliki peran yang cukup banyak sebagai pemisah kata.

\subsection{Filetering}

Tahap Filtering adalah tahap mengambil katakata penting dari hasil token. Bisa menggunakan algoritma stoplist (membuang kata kurang penting) 
atau wordlist (menyimpan kata penting). Stoplist/stopword adalah kata-kata yang tidak deskriptif yang dapat dibuang dalam pendekatan bag-of-words. Contoh stopwords adalah "yang", "dan", "di", "dari”.

\subsection{Stemming}

Stemming adalah proses pemetaan dan penguraian bentuk dari suatu kata menjadi bentuk kata dasarnya. Dalam proses Stemming, array kata diperiksa satu-persatu dengan kata dasar, jika terdapat imbuhan maka dilakukan proses penggantian dengan kata dasar. Stemming disini metodenya memakai Porter Stemming dengan kata dasar berupa array.

\subsection{Klasifikasi}

Pembentukan matrik pada proses klasifikasi menggunakan K-NN melalui proses perhitungan jarak term dokumen latih dan dokumen uji dimana pada penelitian ini mengunakan cosine similarity dengan rumus pecahan 1

Cosine $\mathrm{Q}=\sin \left(Q \cdot D_{i}\right)=\frac{q \cdot D_{i}}{|Q| x\left|Q_{i}\right|}(1)$

Dan dikarenakan jumlah term adalah continuousvalued attributes, maka normalisasi menggunakan nilai interval 0 hingga 1.Tahap awal yaitu penbentukan matrik TF (Term Frequency) serta normalisasi data seperti yang ditunjukkan pada tabel.

\section{Tabel 5. Tabel Matrik TF}

\begin{tabular}{|c|c|c|c|c|c|c|}
\hline & \multicolumn{5}{|c|}{ Tf (term Frequency) } & \\
\hline Term & D1 & $D 2$ & D3 & D4 & D5 & $T f$ \\
\hline antrian & 1 & & & & & \\
\hline bagus & 1 & & & & & \\
\hline baik & & & & 1 & & \\
\hline bersih & & & 1 & & & \\
\hline cekat & & & & & 1 & \\
\hline daftar & & 1 & & & 1 & \\
\hline depo & & 1 & & & & \\
\hline farmasi & & 1 & & & & \\
\hline kamar & & & 1 & & & \\
\hline kurang & & & 1 & & 1 & \\
\hline lama & & 1 & & & 1 & 1 \\
\hline layan & & & & 1 & 1 & 1 \\
\hline mandi & & & 1 & & & \\
\hline obat & & & & & & 1 \\
\hline ramah & & & & 1 & & \\
\hline $\begin{array}{l}\text { perawat } \\
\text { an }\end{array}$ & & & 1 & & & \\
\hline ruang & & & 1 & & & \\
\hline senang & & & & 1 & & \\
\hline suster & & & & 1 & & \\
\hline tugas & & & & & 1 & \\
\hline
\end{tabular}

Tahap kedua menhitung seberapa setring kata itumuncul dalam dokumen yang akan digunakan untuk menhitung besaran bobot kata pada dokumen.
Tabel 5. Tabel Matrik Lengkap dengan TF IDF

\begin{tabular}{|l|l|l|l|l|l|l|l|l|}
\hline & \multicolumn{7}{|c|}{ term frequency $(t f)$} & \multicolumn{1}{l|}{$\begin{array}{l}\text { idf } \\
\text { tog } \\
(n / d f)\end{array}$} \\
\hline term & $d l$ & $d 2$ & $d 3$ & $d 4$ & $d 5$ & $Q$ & $d f$ & \\
\hline antrian & 1 & & & & & & 1 & 0,778 \\
\hline bagus & 1 & & & & & & 1 & 0,778 \\
\hline baik & & & & 1 & & & 1 & 0,778 \\
\hline bersih & & & 1 & & & & 1 & 0,778 \\
\hline cekat & & & & & 1 & & 1 & 0,778 \\
\hline daftar & & 1 & & & 1 & & 2 & 0,477 \\
\hline depo & & 1 & & & & & 1 & 0,778 \\
\hline farmasi & & 1 & & & & & 1 & 0,778 \\
\hline kamar & & & 1 & & & & 1 & 0,778 \\
\hline kurang & & & 1 & & 1 & & 2 & 0,477 \\
\hline lama & 1 & 1 & & & 1 & 1 & 4 & 0,176 \\
\hline layan & & & & 1 & 1 & 1 & 3 & 0,301 \\
\hline mandi & & & 1 & & & & 1 & 0,778 \\
\hline obat & 1 & & & & & 1 & 2 & 0,477 \\
\hline ramah & & & & 1 & & & 1 & 0,778 \\
\hline $\begin{array}{l}\text { perawata } \\
\text { n }\end{array}$ & & & 1 & & & & 1 & 0,778 \\
\hline ruang & & & 1 & & & & 1 & 0,778 \\
\hline senang & & & & 1 & & & 1 & 0,778 \\
\hline suster & & & & 1 & & & 1 & 0,778 \\
\hline tugas & & & & & & & 1 & 0,778 \\
\hline
\end{tabular}

Pada tabel di atas $d f$ yang merupakan jumlah term disemua dokumen, df dari term " lama" = 4 yang diperoleh dari jumlah dari tem "Lama" yang terdapat pada dokumen D1,D2,D5 dan terdapat di query atau data uji. Sedangkan perhitungan idf (inverse document frequensy) diperoleh dari $\log (n / d f)$ dimana $\mathrm{n}$ adalah jumlah semua dokumen termasuk dokumen uji. Idf term "lama" diperoleh dari $\log (6 / 4)=0.176$.

Begitu juga dengan term "layan" = 3 yang diperoleh dari jumlah dari tem "layan" yang terdapat pada dokume D4,D5, dan terdapat di query atau data uji. Sedangkan perhitungan idf (inverse document frequensy) diperoleh dari $\log (n / d f)$ dimana $\mathrm{n}$ adalah jumlah semua dokumen termasuk dokumen uji. Idf term "lama" diperoleh dari $\log (6 / 3)=0.301$.

Untuk term "obat" $=2$ yang diperoleh dari jumlah dari tem "obat" yang terdapat pada dokume D1, dan terdapat di query atau data uji. Sedangkan perhitungan idf (inverse document frequensy) diperoleh dari $\log (n / d f)$ dimana $\mathrm{n}$ adalah jumlah semua dokumen termasuk dokumen uji. Idf term "lama" diperoleh dari $\log (6 / 2)=0.477$. Tahap ketiga menghitung besaran bobot perkata yang terdapat pada dokumen untuk dapat dibandingkan dengan query. Yang di jabarkan pada tabel 6. 
Tabel 6. Matrik Pembobotan Tiap Term

\begin{tabular}{|l|l|l|l|l|l|l|}
\hline & \multicolumn{5}{|c|}{$w d t=t f^{*} i d f$} \\
\hline term & $d 1$ & $d 2$ & $d 3$ & $d 4$ & $d 5$ & $Q$ \\
\hline antrian & 0,778 & 0,000 & 0,000 & 0,000 & 0,000 & 0,000 \\
\hline bagus & 0,778 & 0,000 & 0,000 & 0,000 & 0,000 & 0,000 \\
\hline baik & 0,000 & 0,000 & 0,000 & 0,778 & 0,000 & 0,000 \\
\hline bersih & 0,000 & 0,000 & 0,778 & 0,000 & 0,000 & 0,000 \\
\hline cekat & 0,000 & 0,000 & 0,000 & 0,000 & 0,778 & 0,000 \\
\hline daftar & 0,000 & 0,477 & 0,000 & 0,000 & 0,477 & 0,000 \\
\hline depo & 0,000 & 0,778 & 0,000 & 0,000 & 0,000 & 0,000 \\
\hline farmasi & 0,000 & 0,778 & 0,000 & 0,000 & 0,000 & 0,000 \\
\hline kamar & 0,000 & 0,000 & 0,778 & 0,000 & 0,000 & 0,000 \\
\hline kurang & 0,000 & 0,000 & 0,477 & 0,000 & 0,477 & 0,000 \\
\hline lama & 0,176 & 0,176 & 0,000 & 0,000 & 0,176 & 0,176 \\
\hline layan & 0,000 & 0,000 & 0,000 & 0,301 & 0,301 & 0,301 \\
\hline $\begin{array}{l}\text { mandi } \\
\text { obat }\end{array}$ & 0,000 & 0,000 & 0,778 & 0,000 & 0,000 & 0,000 \\
\hline ramah & 0,000 & 0,000 & 0,000 & 0,778 & 0,000 & 0,000 \\
\hline perawatan & 0,000 & 0,000 & 0,778 & 0,000 & 0,000 & 0,000 \\
\hline ruang & 0,000 & 0,000 & 0,778 & 0,000 & 0,000 & 0,000 \\
\hline senang & 0,000 & 0,000 & 0,000 & 0,778 & 0,000 & 0,000 \\
\hline suster & 0,000 & 0,000 & 0,000 & 0,778 & 0,000 & 0,000 \\
\hline tugas & 0,000 & 0,000 & 0,000 & 0,000 & 0,778 & 0,000 \\
\hline
\end{tabular}

Pada tabel diatas bobot dari term "lama" diperoleh dari perkalian tf dan idf yaitu $1 * 0.176=0.176$ kemudian untuk term "layan" $1 * 0.301=0.301$ dan "obat" didapatkan nilai $1 * 0.477=0.477$. selanjutnya akan dihitung dengan mengunakan Euclidean distance seperti yang di jabarkan detail pada tabel

Tahap keempat pada Tabel 7 pembentukan matrik rentang antara dokumen uji dan dokumen latih serta panjang vector. Perhitungan ini juga disebut sebagai vector space model.

Nilai rentang pada term "lama", "layan" dan term "obat" diperoleh dari perkalian $w$ term dokumen uji dengan $w$ term dari dokumen latih. Untuk term lama Nilai 0.031 pada d1.d2 dan d5 diperoleh dari $0.176 *$ 0.176. untuk term "layan" mendapatkan nilai 0.091 pada dokumen d4 dan d5 di dapat dari $0.301 *$ 0.301. kemudian untuk term "obat" mendapatkan nilai 0.228 pada d1 yang di dapat dari $0.447 * 0.447$ dari nilai rentang ini kemudian di jumlahkan untuk masing masing dokumen. Sedangkan nilai panjang vector adalah nilai kuadrat dari rentang, kemudian dijumlahkan untuk masing-masing dokumen. Hasil dari penjumlahan panjang vector selanjutnya diakar kuadratkan mengunakan rumus SQRT di excel.
Tabel 7. Matrik Pembobotan Tiap Term

\begin{tabular}{|l|l|l|l|l|l|l|l|l|l|l|}
\hline \multicolumn{2}{|l|}{ cosine $=w^{*}{ }^{*}$ wt } & & \multicolumn{5}{|l|}{ panjang veltor $=$ squt(wdt) } & \\
\hline$d I$ & $d 2$ & $d 3$ & $d 4$ & $d 5$ & $d l$ & $d 2$ & $d 3$ & $d 4$ & $d 5$ & $Q$ \\
\hline 0.000 & 0.000 & 0.000 & 0.000 & 0.000 & 0.606 & 0.000 & 0.000 & 0.000 & 0.000 & 0.000 \\
\hline 0.000 & 0.000 & 0.000 & 0.000 & 0.000 & 0.606 & 0.000 & 0.000 & 0.000 & 0.000 & 0.000 \\
\hline 0.000 & 0.000 & 0.000 & 0.000 & 0.000 & 0.000 & 0.000 & 0.000 & 0.606 & 0.000 & 0.000 \\
\hline 0.000 & 0.000 & 0.000 & 0.000 & 0.000 & 0.000 & 0.000 & 0.606 & 0.000 & 0.000 & 0.000 \\
\hline 0.000 & 0.000 & 0.000 & 0.000 & 0.000 & 0.000 & 0.000 & 0.000 & 0.000 & 0.606 & 0.000 \\
\hline 0.000 & 0.000 & 0.000 & 0.000 & 0.000 & 0.000 & 0.228 & 0.000 & 0.000 & 0.228 & 0.000 \\
\hline 0.000 & 0.000 & 0.000 & 0.000 & 0.000 & 0.000 & 0.606 & 0.000 & 0.000 & 0.000 & 0.000 \\
\hline 0.000 & 0.000 & 0.000 & 0.000 & 0.000 & 0.000 & 0.606 & 0.000 & 0.000 & 0.000 & 0.000 \\
\hline 0.000 & 0.000 & 0.000 & 0.000 & 0.000 & 0.000 & 0.000 & 0.606 & 0.000 & 0.000 & 0.000 \\
\hline 0.000 & 0.000 & 0.000 & 0.000 & 0.000 & 0.000 & 0.000 & 0.228 & 0.000 & 0.228 & 0.000 \\
\hline 0.031 & 0.031 & 0.000 & 0.000 & 0.031 & 0.031 & 0.031 & 0.000 & 0.000 & 0.031 & 0.031 \\
\hline 0.000 & 0.000 & 0.000 & 0.091 & 0.091 & 0.000 & 0.000 & 0.000 & 0.091 & 0.091 & 0.091 \\
\hline 0.000 & 0.000 & 0.000 & 0.000 & 0.000 & 0.000 & 0.000 & 0.606 & 0.000 & 0.000 & 0.000 \\
\hline 0.228 & 0.000 & 0.000 & 0.000 & 0.000 & 0.228 & 0.000 & 0.000 & 0.000 & 0.000 & 0.228 \\
\hline 0.000 & 0.000 & 0.000 & 0.000 & 0.000 & 0.000 & 0.000 & 0.000 & 0.606 & 0.000 & 0.000 \\
\hline 0.000 & 0.000 & 0.000 & 0.000 & 0.000 & 0.000 & 0.000 & 0.606 & 0.000 & 0.000 & 0.000 \\
\hline 0.000 & 0.000 & 0.000 & 0.000 & 0.000 & 0.000 & 0.000 & 0.606 & 0.000 & 0.000 & 0.000 \\
\hline 0.000 & 0.000 & 0.000 & 0.000 & 0.000 & 0.000 & 0.000 & 0.000 & 0.606 & 0.000 & 0.000 \\
\hline 0.000 & 0.000 & 0.000 & 0.000 & 0.000 & 0.000 & 0.000 & 0.000 & 0.606 & 0.000 & 0.000 \\
\hline 0.000 & 0.000 & 0.000 & 0.000 & 0.000 & 0.000 & 0.000 & 0.000 & 0.000 & 0.606 & 0.000 \\
\hline 0.259 & 0.031 & 0.000 & 0.091 & 0.122 & 1.470 & 1.470 & 3.255 & 2.513 & 1.788 & 0.349 \\
\hline & & & & & 1.212 & 1.212 & 1.804 & 1.585 & 1.337 & 0.591 \\
\hline
\end{tabular}

Setelah mendapatkan nilai akar (sqrt) dari panjang vector masing-masing dokumen baik dokumen uji maupun dokumen latih, langkah selanjutnya yaitu menghitung nilai kemiripan dengan cara cosine similarity antara vector kata dengan kata kunci dengan tiap dokumen. Prosesnya mengunakan rumus sebagai berikut :

$\operatorname{Cos}(d i)=\sum$ rentang di / $\left[\operatorname{sqrt}\left(\sum\right.\right.$ panjangvektor $\left.d q\right) *$

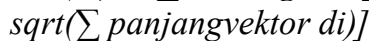

sehingga diperoleh perhitungan cosine untuk masing-masing sebagai berikut :

$$
\begin{array}{ll}
\cos (\mathrm{dQ}, \mathrm{d} 1) & =0.259 /(0.591 * 1.212) \\
\cos (\mathrm{dQ}, \mathrm{d} 2) & =0.031 /(0.591 * 1.212) \\
\cos (\mathrm{dQ}, \mathrm{d} 3) & =0 /(0.591 * 1.804) \\
\cos (\mathrm{dQ}, \mathrm{d} 4) & =0.091 /(0.591 * 1.585) \\
\cos (\mathrm{dQ}, \mathrm{d} 5) & =0.122 /(0.591 * 1.337)
\end{array}
$$

Tahap kelima mengurutkan berdasarkan nilai kimiripan tertinggi untuk digunakan menentukan dokumen mana yang paling mirip dengan query, semakin besar nilainya maka dokumen itu semakin mirim dengan query seperti yang terlihat dalam tabel8.

Tabel 8. Matrik Pembobotan Tiap Term

\begin{tabular}{|l|l|l|l|}
\hline Dokumen & Cosine & Kategori & Sentimen \\
\hline d1 & 0,361 & Apotek & Netral \\
\hline d5 & 0,154 & Pelayanan & negatif \\
\hline d4 & 0,097 & Apotek & negatif \\
\hline
\end{tabular}


Dengan pengambilan tetangga terdekat sebanyak $1(\mathrm{k}=1)$ maka dokumen uji berlabuh ke kategori apotek dengan sentiment netral. Jika diambil $\mathrm{k}=2$ maka dokumen memiliki 2 kemungkinan yaitu apotek dengan sentiment netral dan pelayanan dengan sentiment negative. Sedangkan jika $k=3$ maka dokumen memiliki kesamaan dengan dokumen yang terkategori apotek sebanyak 2 dan sentimen memiliki 2 kesamaan yaitu negatif. Maka dapat di ambil jumlah kemunculan terbanyak kategori dan sentiment. Dengan ini dokumen uji ditetapkan masuk kategori apotek dengan sentiment negatif.

\section{DESAIN SISTEM DAN UJI COBA \\ 5.1 Penanganan Negasi}

Didalam ujicoba penulis akan menjabarkan proses penanganan negasi secara terpisah dengan proses secara keseluruhan karena negasi di tangani secara khusus didalam aplikasi komentar yang dipakai dalam ujicoba "pelayanan sangat baik, akan tetapi lantainya kurang bersih dan sampah menumpuk".

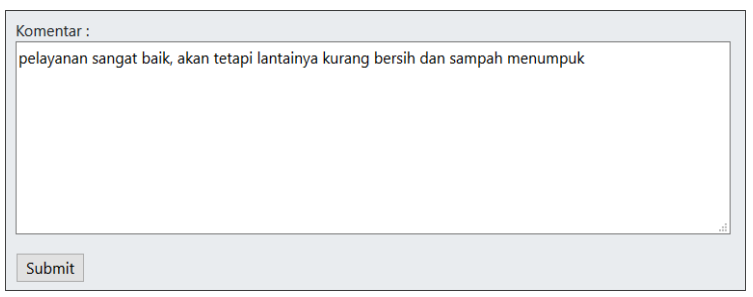

\section{Gambar 2. Input Form}

Komentar akan di input didalam form komentar pada program seperti yang terlihat pada gambar 5.16. ketika di submit kedalam program akan dilakukan pengecekan apakan komentar yang di input mengandung kata negasi atau tidak. Jika ternyata ada kata negasi didalamnya maka sistem akan mencari kedalam database untuk diganti dengan arti kata sesungguhnya berikut daftar kata yang sudah di masukan kedalam database.

Tabel 9. Daftar Kata Negasi

\begin{tabular}{|r|l|l|}
\hline No & Kata Negasi & Kata Pengganti \\
\hline 1 & belum baik & buruk \\
\hline 2 & tidak puas & kecewa \\
\hline 3 & belum bersih & kotor \\
\hline 4 & belum galak & ramah \\
\hline 5 & kurang baik & jahat \\
\hline 6 & tidak menyenangkan & menyedihkan \\
\hline 7 & tidak ramah & galak \\
\hline 8 & tidak terawat & terlantar \\
\hline 9 & kurang Tepat & meleset \\
\hline 10 & tidak cantik & jelek \\
\hline 11 & tidak Bermanfaat & sia-sia
\end{tabular}

Tabel 9. Lanjutan

\begin{tabular}{|r|l|l|}
\hline No & Kata Negasi & Kata Pengganti \\
\hline 12 & tidak Besar & kecil \\
\hline 13 & tidak baik & buruk \\
\hline 14 & kurang ramah & galak \\
\hline 15 & tidak menarik & membesonkan \\
\hline 16 & tidak bersih & kotor \\
\hline 17 & kurang Menarik & mebosankan \\
\hline
\end{tabular}

Sebelum komentar di masukan ke database maka di replace terlebih dahulu dengan tujuan komentar yang di input dapat diterjemahkan oleh sistem dengan arti kata yang jelas.

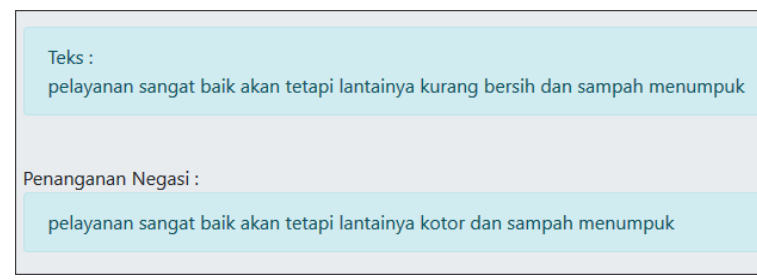

Gambar 3. Hasil Input Dengan Negasi

\subsection{Hasil Uji Coba}

Dari 300 dokumen dalam proses uji coba, terdapat 257 dokument yang berhasil terklasifikasi dengan tepat. 43 tidak berhasil terklasifikasi dengan tepat klasifikasi dibagi menjadi dua bagian yaitu klasifikasi dengan kelas kategori dan kelas sentimen. Rincian jumlah document dapat di lihat pada table.

Tabel 10. Pembagian Data Uji

\begin{tabular}{|r|l|r|}
\hline NO & Kategori & Jumlah Dokumen \\
\hline 1 & Apotik & 14 \\
\hline 2 & Fasilitas & 48 \\
\hline 3 & JadwalPraktek & 35 \\
\hline 4 & Kebersihan & 13 \\
\hline 5 & Pelayanan & 135 \\
\hline 6 & Lain-Lain & 55 \\
\hline & Jumlah & 300 \\
\hline
\end{tabular}

Hasil dari klasifikasi dengan kelas ketegori terdapat 300 data uji dan 275 yang berhasil terklasifikasi dengan benar 25 tidak berhasil terklasifikasi dengan tepat. Sedangkan klasifikasi berdasarkan kelas sentimen 282 yang berhasil terklasifikasi dengan tepat, 18 tidak berhasil terklasifikasi dengan tepat.berikut hasil rician dari ujicoba yang dilakukan. 
Tabel 10. Pembagian Data Uji

\begin{tabular}{|l|r|r|l|r|}
\hline Rician & \multicolumn{1}{|l}{ Jumlah } & \multicolumn{1}{|l|}{ Berhasil } & \multicolumn{1}{l|}{ Tidak } & Prosentase \\
\hline & \multicolumn{1}{|c|}{ data } & & \multicolumn{1}{l|}{ berhasil } & \\
\hline Keseluruhan & 300 & 257 & 43 & $86 \%$ \\
\hline Sentimen & 300 & 282 & 18 & $94 \%$ \\
\hline Kategori & 300 & 275 & 25 & $92 \%$ \\
\hline
\end{tabular}

hasil ujicoba menunjukan bahwa penggunaan metode K-nearest naigbhbor telah memenuhi hipotesis yang di usulkan pada proposal yaitu $80 \%$. Dalam menghitung akurasi keberhasilan digunakan rumus.

$$
\begin{array}{ll}
\text { Akurasi }= & \text { Hasil Klasifikasi Benar } \\
\text { Akumlah Data Uji } & \\
& \frac{257}{300} \\
& \text { Akurasi }=86 \%
\end{array}
$$

Akurasi menunjukkan bahwa klasifikasi dengan menggunakan metode K-Nearest Neighbor Hasil yang baik, Karena proses klasifikasi melalui dua kali proses klasifikasi berdasarkan kategori dokumen dan juga sentimen yang terkandung di dalamnya.

\section{KESIMPULAN}

Berdasarkan hasil ujicoba pada sistem diambil kesimpulan antara lain:

1. Dengan menggunakan metode klasifikasi KNearest Naighbor terhadap dokumen kuesioner dapat disimpulkan hasilnya baik. Dengan tingkat prosestase $87 \%$.

2. Metode K-Nearest Naighbor tidak cocok di pakai untuk pemrosesan skala besar, dikarenakan proses training data akan di ulang-ulang secara keseluruhan setelah terdapat data training yang baru. Proses ini akan mengakibatkan sistem berjalan lambat.

3. Kendala yang dihadapi selama penelitian yaitu pada saat preprosesing dikarenakan data kuesioner yang terdapat pada rumah sakit tidak menggunakan kata baku dan juga banyak mengandung kata singkatan.

4. Sistem yang peneliti bangun ini dapat membantu mendistribusikan pesan yang disampaikan oleh pengguna rumah sakit tepat pada taget yang di maksud.

Sistem yang dibangun juga dilengkapi dengan penangan negasi agar pesan yang dikirim dapat diartikan sesuai dengan maksut dan arti kata yang sesunguhnya.

\section{PUSTAKA}

Admin.2017."Algoritma K-Nearest Neighbor (K-NN)" informatikalogi.com.https://informatikalogi.com/algori tma-k-nn-k-nearest-neighbor)dia akses 03Juli 2017.

Ilyantanto.2011.Stemming Bahasa Indonesia dengan Algoritma Nazief dan Andriani".28-juni2011. (https://liyantanto.wordpress.com/2011/06/28/stemmin g-bahasa-indonesia-dengan-algoritma-nazief-danandriani). Diakses 03 juli 2017.

Li Baoli, Yu Shiwen, and Lu Qin, An Improved k-Nearest Neighbor Algorithm for Text Categorization, Department of Computer Science and Technology Peking University, Beijing, P.R. China, 100871, 2003.

Lu Qin, An Improved k-Nearest Neighbor Algorithm for Text Categorization, Department of Computer Science and Technology. Peking University, Beijing, P.R. China, 100871, 2003.

Mohammad Rezwanul Huq, Ahmad Ali, Anika Rahman. 2017. "Sentiment Analysis on Twitter Data using KNN and SVM". Vol. 8, No. 6, 2017. (IJACSA) International Journal of Advanced Computer Science and Applications.Dhaka, Bangladesh.

Mesariya.P, Madia.N, Kumar.A. 2016. "Document Ranking using Customizes Vector Method - A Review", International Journal of Computer Science and Mobile Computing (IJCSMC). pg. 287-290, Vol.5 Issue. 3

Taeho Jo. 2017. "Using K Nearest Neighbors for Text Segmentation with Feature Similarity". Department of Computer and Information Communication Engineering. Hongik University 